\title{
A fronteira internacional do Amapá e o Acordo-Quadro
}

\author{
The international framework of Amapá and the framework agreement
}

\section{Bárbara Lis Rabelo Brito ${ }^{1}$ e Daguinete Maria Chaves Brito $^{2}$ e Andréia Jayme Batista ${ }^{3}$}

\author{
1 Advogada e Acadêmica do Curso de Relações Internacionais da Universidade Federal do Amapá. E-mail: barbaralis@uol.com.br \\ 2 Doutora em Ciências Sociais. Professora Adjunta do Colegiado de Geografia, Campus Marco Zero da Universidade federal do Amapá. E- \\ mail: dagnete@uol.com.br \\ 3 Mestre Desenvolvimento Regional. Professora da Universidade Federal do Amapá, do Colegiado de Relações Internacionais. Mestranda \\ do Programa de Pós-Graduação Mestrado em Desenvolvimento Regional - UNIFAP; E-mail: andreiajbatista@hotmail.com
}

\begin{abstract}
RESUMO: O Estado do Amapá tem como uma de suas características o isolamento terrestre com o restante do Brasil. Porém se integra com o Platô das Guianas, via Ponte Binacional, inaugurada parcialmente em 2015. Fato que ocorreu com a assinatura, entre o Brasil e a França do Acordo-Quadro/1996. Nesta perspectiva a pesquisa se propôs a avaliar as finalidades do Acordo e quais seus desdobramentos para a população da área de fronteira. Tendo como objetivo a análise do seu conteúdo, considerando os pressupostos da Convenção de Viena de 1969. Metodologicamente optou-se pela pesquisa qualitativa no teor do Acordo.
\end{abstract}

Palavras-chave: Amapá. Fronteira. Legislação. Acordo-Quadro.

\begin{abstract}
The state of Amapá has as one of its characteristics the terrestrial isolation with the rest of Brazil. However, it is integrated with the Plateau of the Guianas, via the Binational Bridge, which was partially inaugurated in 2015. A fact that occurred with the signing between Brazil and France of the Framework Agreement / 1996. In this perspective the research proposed to evaluate the purposes of the Agreement and what its consequences for the population of the border area. Aiming to analyze its content, considering the assumptions of the Vienna Convention of 1969. Methodologically, the qualitative research was chosen in the content of the Agreement.
\end{abstract}

Keywords: Amapá. Border. Legislation. Framework Agreement.

Sumario: Introdução - 1 A Constituição do Acordo-Quadro - 20 Acordo-Quadro firmado entre Brasil e França: 2.1 O Preâmbulo do Acordo-Quadro, 2.2 O Texto do Acordo-Quadro - Considerações Finais - Referências

\section{INTRODUÇÃO}

As relações na fronteira entre Brasil (Amapá) e França (Guiana Francesa) historicamente são conflituosas. Nos séculos XVIII e XIX a área passou a ser considerada uma região contestada. No final do século XIX houve a definição da fronteira entre as duas nações, passando o rio Oiapoque a ser o limite natural entre Amapá e Guiana Francesa. Entretanto, os conflitos 
permaneceram e no final do século XX, representantes das duas repúblicas assinaram um Acordo-Quadro que estabeleceu a cooperação na gestão da área fronteiriça.

Embora este Acordo tenha sido estabelecido em 1996 e promulgado pelo Brasil em 1997, ainda não foi totalmente executado, pois os governantes dos dois Estados não conseguem desenvolver as atividades e programas que desencadeariam no desenvolvimento socioeconômico das populações da área. Pois, para que o desenvolvimento ocorra há necessidade do livre intercâmbio de experiências científicas e culturais e do mútuo auxílio tecnológico e financeiro entre os Estados, afim de facilitar as relações internacionais entre os povos.

No caso da região fronteiriça franco-brasileira, já existem vários Acordos que podem, de forma direta e indiretamente, contribuir para a solução dos conflitos existentes na área. Entretanto, um dos mais significativos é a execução plena do Acordo-Quadro de Cooperação, celebrado entre Brasil e França em 1996. Este Acordo traz em seu bojo nove artigos que pressupõem a gestão compartilhada na área de fronteira, tais como: o desenvolvimento de instrumentos de cooperação econômica, cultural, científica e técnica; intercâmbio comercial e financeiro e reuniões bilaterais em ambos os países. Analisando os artigos do Acordo é possível identificar a intenção de cooperação entre os dois governos.

Portanto, o acordo deveria contribuir de forma significativa para a concretização do Princípio de Cooperação entre os Povos, pois prevê a prática de um grande intercâmbio de conhecimentos científicos e recursos tecnológicos entre os países. A concretização do Acordo-Quadro e a aplicação deste princípio minimizariam os conflitos existentes na área fronteiriça. Assim, este estudo se justifica pela necessidade de analisar o teor do Acordo-Quadro assinado entre as duas nações, o qual prevê uma gestão compartilhada da faixa fronteira de forma diferenciada do restante do território dos dois Estados.

Este estudo tem como tema o Acordo-Quadro e a Fronteira Internacional do Amapá, tendo como questão norteadora a averiguação de como foi constituído e como ocorre à execução do Acordo na Faixa de Fronteira Amapá-Guiana Francesa? A hipótese principal para responder a esta indagação é que embora o Acordo tenha sido elaborado tendo como base legal a Convenção de Viena, de 1969, não há de fato a execução do Acordo-Quando e que este, ainda, permanece no campo do planejamento, sem influenciar no cotidiano das populações dos dois lados da fronteira.

Para averiguar a questão norteadora e confirmar ou refutar sua hipótese foi necessário estabelecer como objetivo geral: Analisar o Acordo-Quadro, assinado entre o Brasil e a França, em 1996 e ratificado internamente em 1997, considerando os pressupostos da Convenção de Viena de 1969. Os objetivos específicos foram assim estruturados: a) Expor e avaliar o Acordo-Quadro assinado entre o Brasil e França, em 1996, observando seu processo de constituição e b) Averiguar quais efeitos este Tratado pode trazer para a população envolvida na área fronteiriça entre Amapá e Guiana Francesa.

Para alcançar estes objetivos a metodologia utilizada foi a qualitativa, por meio de coleta de informações teóricas com a finalidade de realizar levantamentos que possibilitem analisar o problema apresentado, ou seja, examinar como o Acordo-Quadro foi negociado e elaborado, bem como está sendo implementado pelos Estados-Partes. Esta metodologia foi 
desenvolvida em diversas fases, obedecendo às exigências expostas nos objetivos específicos. A técnica empregada na pesquisa envolveu levantamento bibliográfico, análise documental e pesquisa em sites e confrontação entre os diversos dados coletados, evolvendo diversos autores, tanto da área do direito como de ciências afins.

Para alcançar os objetivos propostos este estudo foi dividido em duas partes, além desta introdução e das considerações. A primeira averiguou quais os principais interessados no Acordo e avaliou o preâmbulo do ato, que é a parte introdutória de qualquer Tratado Internacional assinado entre dois ou mais Estados. A segunda parte ponderou sobre o que é exposto no texto do Acordo, considerando os artigos que o compõe, desde o objeto, os temas de interesse e os Tratados que foram ab-rogados por este, além de fazer uma síntese sobre seus efeitos para a população da área, principalmente a sua aplicabilidade socioeconômica.

\section{A CONSTITUIÇÃO DO ACORDO-QUADRO}

O limite entre o Amapá e Guiana Francesa sempre foi alvo de conflitos e de negociações diplomáticas, desde o período de colonização e sua definição ocorreu após a negociação e assinatura de vários Tratados. Entretanto, mesmo com a delimitação oficial definida, a partir da assinatura do Laudo de Berna ou Laudo Suíço, em 1900, a faixa de fronteira entre os dois Estados é um espaço conflituoso e não desenvolvido socioeconomicamente, carecendo de atenção especial por parte das autoridades dos dois países, principalmente com relação aos altos índices de criminalidade que é recorrente na área, inclusive com vários assassinatos dos dois lados da fronteira (BRITO, 2010).

$\mathrm{Na}$ tentativa de promover o desenvolvimento socioeconômico da área de fronteira entre o Amapá e a Guiana Francesa e diminuir os constantes casos de violência que são recorrentes nesta região, aconteceu em 28 de maio de 1996, em Paris, a assinatura do AcordoQuadro, um Acordo bilateral que tem como objetivos garantir o estabelecimento de planejamento do território mediante a uma série de iniciativas institucionalizadas de integração e cooperação entre o Brasil e a França, mais especificamente na faixa de fronteira AmapáGuiana Francesa (BRASIL, Decreto no 2.200/1997).

Em geral, os Acordos relacionados à faixa de fronteira têm como preocupação principal a delimitação dos Estados, tendo como principal objetivo a sua defasa territorial. Entretanto, - Acordo-Quadro/1996, tem como maior preocupação institucionalizar a cooperação fronteiriça, demonstrando um novo direcionamento na política internacional brasileira em relação a sua área de fronteira. Segundo Martins (2008) esse movimento supera a visão geopolítica que serviu de modelo ao Estado em décadas anteriores. Para a autora

A visão geoeconômica cartografa os espaços segundo uma lógica norteada por interesses gerados na transnacionalização dos mercados e na ampliação da competição no campo econômico mundial; dessa forma, faz parte das estratégias desenvolvidas pelos Estados nacionais para enfrentar as provocações imperativas da globalização (Martins, 2008, p. 95 - 96). 
Para se constituir um Ato Internacional há várias formalidades que devem ser respeitadas e são necessárias sete fases ou etapas (Negociação, Assinatura, Ratificação, Promulgação, Publicação e Registro), porém, é indispensável uma fase que antecede todas essas, que é o interesse e a necessidade em começar as negociações, são os atos preliminares de que qualquer Tratado Internacional pressupõe (MAZZUOLI, 2011).

E esse interesse começou em novembro de 1995, quando o então Governador do Estado do Amapá, João Alberto Rodrigues Capiberibe, em viagem oficial à Caiena (Guiana Francesa) demonstrou interesse em negociar um Acordo que beneficiasse os dois Estados. Segundo Martins (2008, p. 96), após “décadas de relativa indiferença, foi a primeira iniciativa na direção de encadear negociações para estabelecer laços de cooperação com a Guiana Francesa".

O interesse do governo em firmar um Acordo para a região fronteiriça é o primeiro passo para a concretização do Acordo-Quadro que foi assinado no ano seguinte e surgiu da necessidade de proporcionar o desenvolvimento socioeconômico para a área e minorar os casos de violência que são comuns à área. É interessante lembrar que as relações diplomáticas entre Brasil e França são recorrentes, existem vários Tratados, tanto bilaterais, quanto multilaterais assinados entre os dois Estados.

Outro passo importante ocorreu em janeiro de 1996, também em viagem oficial à Europa, o governador do Estado ao visitar a França procurou sensibilizar as autoridades francesas da necessidade em promover a cooperação fronteiriça entre o Amapá e a Guiana Francesa. Essa ação do governador foi possível com a descentralização promovida pelo neoliberalismo. A respeito dessa descentralização Lafer (1994) afirma que

\footnotetext{
Existe, assim, respeitada a competência do Poder Executivo federal na condução das relações externas do país, uma diplomacia federativa que se exerce como parte do encaminhamento e da projeção dos interesses nacionais. O governo central, não atua isoladamente nessa tarefa em relação aos poderes da Federação. É uma atividade cuja importância se faz sentir cotidianamente em múltiplas iniciativas, como ultimamente, nas nossas relações com países limítrofes, na condução de legítimas aspirações locais que envolvem projetos de integração física e econômica (LAFER, p. 29).
}

Ou seja, embora os processos de negociações e execução dos Atos Internacionais seja prerrogativa exclusiva da União, conforme determina a Constituição da República Federativa do Brasil (CRFB), de 1988, em seu art. 84, inciso VII, o interesse e a participação do governante amapaense foi importante para o início e concretização da assinatura do Acordo-Quadro entre Brasil e França, havendo, inclusive, uma transição da percepção de fronteira como divisão de soberania para um espaço com grandes potencialidades econômicas e desenvolvimento socioambiental.

Estas ideias são corroboradas por Coelho (1992), que afirma que as faixas de fronteira na Amazônia são espaços favoráveis ao desenvolvimento da cooperação. Isto é, para este autor há a possibilidade da promoção de intercâmbios, que tenham por objetivos a definição de estratégias para solucionar problemas relacionados ao desenvolvimento socioeconômico 
das populações que habitam essas áreas.

Após o convencimento da necessidade de estabelecer um Ato Internacional, específico para atender as necessidades da área de fronteira Amapá-Guiana Francesa, a negociação do Acordo-Quadro ocorreu em tempo record, isto é, o período de negociação aconteceu de janeiro a maio de 1996. O que significa que as partes contratantes não tinham grandes divergências, pois um dos pressupostos dos Acordos Internacionais, segundo Piovesan (2003), são as concessões mútuas. Ou seja, todos os envolvidos no Ato devem ceder alguns direitos em benefício da coletividade.

Embora o governante do Amapá tenha sido o grande impulsionador e o maior interessado na elaboração e assinatura do Tratado, a fase de negociação propriamente dita é uma prerrogativa exclusiva, no Brasil, da União e ocorreu com negociadores indicados pelo Ministério das Relações Exteriores, representando o governo brasileiro e agentes diplomáticos indicados pela França, pois o Acordo é bilateral, sem a necessidade de conferências ou congressos entre os dois países ou envolvimento de Estados ou Organizações Internacionais aIheios a questão.

Após a negociação e a elaboração do texto que, de acordo com Mello (2004), se subdivide em duas partes (preâmbulo e texto do Tratado), houve a assinatura, que ocorreu em solenidade conjunta entre os dois Estados. A assinatura do Acordo-Quadro aconteceu em 28 de maio de 1996, em Paris, na França.

Portella (2014) afirma que a autoridade competente para assinar um Acordo Internacional é qualquer representante do Brasil que tenha em sua posse uma Carta de Plenos Poderes emitida pelo Presidente da República, portanto, é comum que o Ministro das Relações Exteriores assine estes Atos Internacionais. Foi o que ocorreu com o Acordo em discussão, que foi assinado pelo Ministro das Relações Exteriores, à época, Luiz Felipe Lampreia, representando o Governo da República Federativa do Brasil e pelo Ministro dos Negócios Estrangeiros, Hervé de Charette, representando o Governo da República Francesa (BRASIL. Decreto no 2.200/1997).

Outro passo importante para a execução deste Tratado, no Brasil, foi sua aprovação pelo Congresso Nacional, conforme dispõe o art. 49, inciso I da CRFB/1988. Essa aprovação ocorreu a partir da publicação do Decreto Legislativo no 5, de 28 de janeiro de 1997, que em seu art. 10 determina que fica "[...] aprovado o texto do Acordo-Quadro sobre Cooperação celebrado entre o Governo da República Federativa do Brasil e o Governo da República Francesa, em Paris, em 28 de maio de 1996" (BRASIL, Decreto Legislativo no 5/1997, art. 1으).

Esta é uma etapa incomum para os Acordos, pois segundo Mazzuoli (2011) a validação de Acordos no Brasil é concluída pelo Chefe de Estado, sem consulta ao Poder Legislativo. Entretanto, é uma prática no Brasil, que todos os Atos Internacionais sejam analisados e aprovados pelo Congresso Nacional, ou seja, se torna um peso para fortalecer o Tratado.

O Acordo-Quadro de Cooperação é finalmente promulgado pelo Poder Executivo por meio do Decreto no 2.200, de 08 de abril de 1997, deste modo, criando obrigações jurídicas no âmbito interno e externo, representando a ratificação do Acordo pelo Estado brasileiro e consequentemente a publicação do texto no Diário Oficial da União, incorporando, assim, o 
Tratado ao ordenamento jurídico interno como lei ordinária, ou seja, tornando o cumprimento do Acordo obrigatório para todos.

\section{ACORDO-QUADRO FIRMADO ENTRE BRASIL E FRANÇA}

Nesta seção serão analisados o teor do Acordo-Quadro assinado entre Brasil e França, em 1996, que tem como principal finalidade subsidiar ações de desenvolvimento na fronteira Amapá-Guiana Francesa, considerando o seu preâmbulo, que delimita suas características, seus contratantes e suas pretensões. Assim, como será ponderado sobre seu texto principal que é composto por nove artigos, mas com grande profundidade e amplitude.

\subsection{O PREÂMBULO DO ACORDO-QUADRO}

O preâmbulo de qualquer Ato Internacional, segundo Mello (2004) reflete os motivos de sua concretização, fornece os elementos essenciais a sua interpretação, ou seja, é a parte introdutória do Acordo, é neste preâmbulo que se faz a apresentação do Tratado Internacional. O Acordo-Quadro assinado entre o Brasil e a França, conforme o Decreto no 2.200, de abril de 1997, que o promulgou, expressa em sua parte introdutória o seguinte texto:

\footnotetext{
Acordo-Quadro de Cooperação entre o Governo da República Federativa do Brasil e o Governo da República Francesa (doravante denominados "Partes Contratantes"), Convencidos de que a participação ativa do Brasil e da França nas relações políticas e econômicas internacionais, bem como sua contribuição ao diálogo das culturas, favorecem o estabelecimento de uma ordem mundial mais aberta e mais equânime;

Animados pelo desejo de instituir uma nova parceria e de reforçar suas tradicionais relações de amizade pela criação de um mecanismo de consultas bilaterais regulares e pelo aprofundamento do diálogo político;

Ciosos de promover a cooperação nos campos econômico, cultural, científico e técni$\mathrm{co}$, bem como em novos setores de interesse comum;

Desejosos de desenvolver suas relações de boa vizinhança na zona fronteiriça situada de um lado e de outro de sua fronteira comum;

Tendo em vista ser o Brasil membro do Mercosul e a França, da União Européia, e conscientes da importância do diálogo cada vez mais estreito que se desenvolve entre esses dois grupos regionais,

Acordam o seguinte:
}

Na primeira parte do preâmbulo é expresso o tipo de Ato Internacional que está sendo proposto, um Acordo, com a denominação especifica de Acordo-Quadro, o que não é uma obrigatoriedade, pois a denominação Acordo, para os Tratados Internacionais é caracterizado como um Ato de natureza econômica, financeira, comercial, científica, técnica ou cultural, como preconizado por Mazzuoli (2011). Entretanto, o destaque neste caso, e que o autor, também, explica que os Acordos são Atos Internacionais típicos para tratar de assuntos de fronteira. Tanto bilateralmente, como multilateralmente. Além de particularizar que é um Acordo de Cooperação.

Planeta Amazônia: Revista Internacional de Direito Ambiental e Políticas Públicas 
Outro item importante com relação a esta primeira parte do preâmbulo é a especificação dos Estados participantes "a República Federativa do Brasil e a República Francesa" que a partir da assinatura do Acordo serão denominados de "Partes Contratantes". Ou seja, é neste item que se observa, se o Acordo é bilateral ou multilateral, bem como, quais são os Estados que participam efetivamente do Ato.

A segunda parte do Acordo está relacionada às justificativas para se celebrar o Ato, expondo que o Brasil, assim com a França tem participação ativa nas relações políticas e econômicas em nível internacional, desta forma contribuindo para o diálogo das diversas culturas recorrentes no globo, além dos dois Estados estarem empenhados em estabelecer uma ordem mundial aberta e equânime. Com essa justificativa os dois Estados demonstram que se empenham por uma cultura da paz no globo e de desenvolvimento socioeconômico internacional.

Com relação à terceira parte do preâmbulo do Acordo, expõe-se o interesse em instituir uma nova parceria entre as duas nações, além de reforçar as relações de amizade que são tradicionais entre elas. É interessante citar que esta tradição é relativamente recente, pois as relações entre França e Brasil antes de 1900 foram bastante conflituosas, carecendo de intervenção arbitral para definir seus limites. Porém, a partir da definição as relações entre os dois Estados são cordiais, inclusive com as instituições de vários Tratados.

Essa parte do preâmbulo, também, dispõe que o Acordo é criado com o objetivo de instituir mecanismos de consultas bilaterais que deverão ser regulares, com isso aprofundando o diálogo político entre as partes contratantes. O que é de grande importância para o desenvolvimento socioeconômico da área de fronteira em questão e ainda, para amenizar os constantes conflitos entre os usuários da área.

O quarto item expresso no preâmbulo versa sobre os temas que a cooperação entre os Estados deve promover, e são citados os campos: econômico, cultural, científico e técnico, o que para Mazzuoli (2011) é pertinente para um Acordo. Este item, também, indica o envolvimento de novos setores de interesse comuns entre os Estados-participantes do Acordo.

O penúltimo item do preâmbulo destaca o interesse em desenvolver as relações de boa vizinhança entre os dois Estados, corroborando com o terceiro item que expõe a relação de amizade existente entre os dois acordantes. Com relação a este item é interessante destacar que as relações de "boa vizinhança" nem sempre ocorre. Pois, é comum na mídia local notícias de animosidade entre a população da área, ocorrendo, inclusive, assassinatos em ambos os lados da fronteira.

A última etapa do preâmbulo dispõe sobre a participação dos dois Estados em blocos econômicos, o Brasil no Mercado Comum do Sul (MERCOSUL) e a França, na União Europeia, explicando a importância que estas Organizações Internacionais podem ter para o desenvolvimento socioeconômico das populações dos Estados participantes do Acordo, pois, existem entre os dois blocos várias parcerias, inclusive comerciais.

Ou seja, o preâmbulo do Acordo-Quadro segue as formalidades de qualquer Ato Internacional, tendo como base a Convenção de Viena de 1969. Isto é, expõe o tipo de Ato, as partes contratantes, as especificidades, as áreas de interesse do Acordo e as relações que os dois 
países mantêm entre si. É importante destacar que os dois Estados participantes deste Acordo são signatários da Convenção de Viena/1969, portanto, seguem o rito preconizado por tal Convenção.

\subsection{O TEXTO DO ACORDO-QUADRO}

Após a análise do preâmbulo se inicia a avaliação da redação do texto do Tratado, que pode ser denominado, também, de corpo do Tratado. Neste item são definidos os temas e, principalmente, os deveres e obrigações de cada Estado Contratante, quando da sua assinatura. Para Mello (2004), o texto do Acordo pode ser longo, com vários artigos, ou podem ser curtos, não existindo uma regra que especifique o tamanho padrão de Tratados. O que se observa no Acordo-Quadro assinado entre Brasil e França, em 1996 é que se trata de um Ato relativamente curto, com apenas nove artigos, porém com profundidade razoável em vários temas, é o que será ponderado a seguir.

$\mathrm{O}$ primeiro artigo do Acordo-Quadro se refere às partes contratantes e expressa mais uma vez, os objetivos políticos que o Acordo tem em estabelecer entre os dois Estados, que é o de fortalecer o desenvolvimento da cooperação em diversos temas de interesses entre os dois Estados. Esses temas são prioritários para a região e devem ser executados para que a população da faixa fronteiriça perceba os benefícios do Acordo, neste sentido, o art. 1으, do anexo do Decreto 2.200/1997, expõe que

As Partes Contratantes dispõem-se a conferir renovado impulso às relações bilaterais. Com esse objetivo, empenhar-se-ão em favorecer os contatos políticos em todos os níveis entre os dois Estados e em reforçar o desenvolvimento da cooperação econômica, cultural, científica e técnica, segundo as modalidades definidas no presente Acordo (BRASIL. Decreto no 2.200/1997, art. 1으 - Anexo).

Com base na descrição deste artigo é possível perceber que há interesse em impulsionar as relações bilaterais, na área fronteiriça entre o Amapá e a Guiana Francesa. O texto, também indica que os contratantes se empenharão em fortalecer os contatos políticos em todos os níveis, o que significa, que não somente a União fará parte das reuniões de planejamento, incluindo neste rol, representantes do Estado do Amapá e, até dos municípios envolvidos, como Oiapoque e Laranjal do Jari, que são os dois municípios que fazem fronteira com a Guiana Francesa.

$\mathrm{O}$ artigo em questão, também, determina o reforço do desenvolvimento na cooperação, além de especificar quais as áreas terão prioridade nesta cooperação, que são as áreas: econômica, cultural, científica e técnica, o que significa que o Acordo é muito amplo, abrangendo praticamente todos os temas socioeconômicos de uma população e determina, ainda, a cooperação técnica, que seria a transferência de tecnologias, em termos gratuitos de um Estado para outro.

Com relação ao artigo 10 é possível inferir, segundo Góes (2014), que nenhuma medida de cooperação prevista foi executada até 2014. O que indica que o Acordo se encontra 
somente em nível de discussão, e como consequência de sua não implementação efetiva a população continua convivendo com todos os problemas socioeconômicos recorrentes na área e em clima de tensão, principalmente, no que se refere à violência, sobretudo, nas áreas de garimpo.

A seguir será discutido o artigo segundo do Acordo-Quadro, que possui três itens e versa sobre a instituição de uma Comissão Geral franco-brasileira e suas funções, dos períodos e locais de reuniões, dos representantes dos Estados. Além da constituição de grupos de trabalhos que serão necessários para subsidiar o planejamento da faixa de fronteira, conforme exposto a seguir:

1. As Partes Contratantes decidem reunir bianualmente uma Comissão Geral francobrasileira, que terá a missão de promover o diálogo político, de coordenar os diferentes aspectos das relações bilaterais e de estabelecer um programa de trabalho para o biênio seguinte.

2. A Comissão Geral franco-brasileira, que se reunirá alternadamente no Brasil e na França, estará integrada por representantes dos dois Governos, sob a presidência dos Ministros das Relações Exteriores. As Partes Contratantes determinarão, de comum acordo e por via diplomática, a data e a agenda das reuniões.

3. Os Grupos de Trabalho previstos nos diferentes acordos de cooperação setorial em vigor, ou que venham a ser criados, relatarão bianualmente seus trabalhos à Comissão Geral franco-brasileira (BRASIL, Decreto o 2.200/1997, art. 2o - Anexo).

O artigo segundo do Acordo-Quadro, em seu primeiro item expõe sobre os encontros que serão necessários para executar o planejamento socioeconômico e técnico da área fronteiriça, indica, também, a instituição de uma Comissão Geral franco-brasileira que se reunirá bianualmente, tendo como objetivos principais a promoção do diálogo político e a coordenação dos diferentes aspectos das relações bilaterais, além de estabelecer um programa de trabalho para cada biênio seguinte.

No item dois do artigo além de determinar que as reuniões da Comissão Geral francobrasileira devam ocorrer alternadamente, no Brasil e na França, tendo como presidência os Ministros das Relações Exteriores dos dois Estados, refere, também, que a agenda das reuniões de trabalho e as datas de ocorrência devam ser definidas de comum Acordo e por via diplomática. Já o terceiro item deste artigo traz a previsão de constituição de Grupos de TrabaIhos setoriais e que terão a missão de relatar seus trabalhos à Comissão Geral francobrasileira.

Neste artigo é possível perceber que há especificação de como o Acordo será executado, desde os temas a serem abordados, como ocorrerão os encontros e quem serão os representantes de cada Estado. Segundo Góes (2014) esses encontros estão ocorrendo, o que demonstra, mais uma vez que a execução do Acordo está em seu estágio inicial, sem a ocorrência de medidas práticas.

No artigo terceiro do Acordo-Quadro é destacada, em seus três itens, a adaptação dos instrumentos de cooperação entre os dois Estados, a constituição de subcomissões e como ocorrerão seus encontros, que deve acontecer, quando necessário, também, nos anos em 
que a Comissão Geral franco-brasileira não se reunir, além de prever a constituição de dois grupos de avaliação e acompanhamento com objetivos específicos de avaliar e acompanhar as duas subcomissões. É o que está exposto a seguir:

1. As Partes Contratantes confirmam o espírito no qual estabeleceram os instrumentos de cooperação cultural, científica e técnica e decidem adaptá-los às novas condições da cooperação franco-brasileira.

2. Com tal objetivo, as Partes Contratantes reunirão bianualmente, sob a égide da Comissão Geral franco-brasileira, uma Comissão Científica e Técnica e uma Comissão Cultural e Lingüística encarregadas de estabelecer um programa comum de cooperação em suas respectivas áreas de atuação.

3. Entre duas sessões da Comissão Geral, reunir-se-á, quando necessário, um grupo de avaliação e de acompanhamento encarregado das questões científicas e técnicas e um grupo de avaliação e de acompanhamento encarregado dos assuntos culturais lingüísticos (BRASIL. Decreto no 2.200/1997, art. 3o - Anexo).

Neste artigo é possível inferir, no primeiro item, que as partes contratantes se subsidiam dos pressupostos da cooperação cultural, científica e técnica de modo geral, porém, com adaptações para as novas condições de cooperação franco-brasileira, o que demonstra que a área fronteiriça necessita de tratamento especifico, conforme a situação real da região e de sua população.

Tendo como fundamento a adaptação da cooperação cultural, científica e técnica, as partes contratantes, segundo especificado no item dois do artigo, criarão duas comissões específicas que têm a denominação de (1) Comissão Cientifica e Técnica e (2) Comissão Cultural e Linguística. Estas comissões têm como objetivo estabelecer programas comuns de cooperação entre os dois Estados, em suas áreas de atuação. Já o terceiro item deste artigo define a instituição dos grupos de avaliação e acompanhamento dessas duas subcomissões. É pertinente destacar que estas reuniões vêm ocorrendo nos anos de vigência do Acordo.

Com relação ao artigo quarto, o Acordo possui quatro itens que expõe, basicamente, a intenção de desenvolver relações econômicas, a criação de uma Comissão Econômica francobrasileira, estipula quando ocorrerão as reuniões dessa comissão e prevê a instituição de grupos de trabalhos setoriais ou temático relacionados à área econômica, assim expostos:

1. As Partes Contratantes reafirmam sua intenção de desenvolver relações econômicas especialmente em matéria de intercâmbio comercial, de investimentos e de cooperação financeira e, em especial, a promoção de iniciativas no nível de pequenas e médias empresas dos dois países.

2. Para esse fim, as Partes Contratantes reunirão bianualmente, sob a égide da Comissão Geral, uma Comissão Econômica franco-brasileira, que sucederá à Comissão Econômica franco-brasileira para Indústria e Comércio, criada pelo Comunicado Conjunto franco-brasileira, em 6 de novembro de 1975.

3. Entre duas sessões da Comissão Geral, a Comissão Econômica franco-brasileira reunir-se-á periodicamente sob a presidência dos Ministros competentes em matéria econômica internacional ou de seus representantes.

4. Com o objetivo de associar mais estreitamente as empresas dos dois países no de-

Planeta Amazônia: Revista Internacional de Direito Ambiental e Políticas Públicas 
senvolvimento da cooperação econômica franco-brasileira, a Comissão Econômica franco-brasileira poderá fazer representantes do setor privado participarem de seus trabalhos e criar grupos de trabalho setoriais ou temáticos nos campos julgados prioritários pelas Partes Contratantes (BRASIL. Decreto no 2.200/1997, art. 4ㅇ- Anexo).

No primeiro item deste artigo há a reafirmação de que o Tratado, também, prevê a intenção de desenvolver o intercâmbio econômico, abrangendo as áreas comerciais, investimentos e financeira e ainda dá tratamento especial a promoção de iniciativas de desenvolvimento das pequenas e médias empresas dos dois Estados. Já o segundo item trata da substituição da Comissão Econômica franco-brasileira para Indústria e Comércio pela Comissão Econômica franco-brasileira, o que demonstra uma adaptação para a realidade atual como já previsto em artigo anterior.

Enquanto que o item três dispõe sobre como ocorrerá às reuniões da Comissão Econômica franco-brasileira, sendo que estas reuniões serão presididas pelos Ministros responsáveis pela área econômica, ou por seus representantes. A participação de especialistas em determinada área é uma medida recorrente nos Tratados firmados entre países. Já o item quatro prevê a participação do setor privado na comissão econômica, inclusive fazendo parte de grupos de trabalhos setoriais ou temáticos.

O artigo quinto está dividido em duas partes, a primeira trata das consultas políticas que devem ser permanentes, inclusive nos anos em que a Comissão Geral franco-brasileira não se reunirá e a segunda, dispõe sobre a formalização de tais consultas política, como: a data, a agenda, o nível e o local de cada reunião, conforme disposto a seguir:

1. Nos anos em que a Comissão Geral não se reunir, as Partes Contratantes manterão consultas políticas em nível de altos funcionários, a fim de proceder a um amplo intercâmbio de idéias sobre as questões bilaterais correntes, bem como sobre os assuntos internacionais de interesse comum.

2. Essas consultas realizar-se-ão, alternadamente, no Brasil e na França. As datas, a agenda, o nível e o local de cada reunião serão determinados de comum acordo pela via diplomática (BRASIL. Decreto no 2.200/1997, art. 5o - Anexo).

O artigo, em sua primeira parte, expõe a necessidade dos dois Estados manterem o diálogo a respeito das ações que forem executadas, tendo como base o Acordo-Quadro, ou seja, as consultas políticas, com a finalidade de proceder o amplo intercâmbio de ideias, sobre as principais questões que envolvem os dois Estados-Partes e sobre os assuntos internacionais de interesse comum.

Já a segunda parte trata da ocorrência destas consultas públicas, que devem acontecer alternadamente no Brasil e na França e que, as datas, o que será discutido (agenda), o nível e o local deverão ser decididos conjuntamente e de comum acordo, pela via diplomática. Ou seja, todas as ações que tem como base o Acordo-Quadro devem ser discutidas por via diplomática.

O sexto artigo, é o último a tratar especificamente das características do AcordoQuadro e tem como foco a realização de consultas políticas para o bom desempenho da coo- 
peração transfronteiriça, considerando todos os temas abordados nos artigos anteriores conforme exposto a seguir:

1. As Partes Contratantes realizarão a cada ano consultas visando ao favorecimento da cooperação transfronteiriça em todos os domínios de interesse comum e ao exame dos projetos desenvolvidos pelas coletividades locais dos dois países, no quadro das legislações nacionais. Representantes dessas coletividades locais poderão estar associados a esses trabalhos.

2. Esse grupo de consulta reunir-se-á alienadamente no Brasil e na França (BRASIL. Decreto no 2.200/1997, art. 6으- Anexo).

O principal fato a ser discutido neste artigo é o exame dos projetos desenvolvidos pelas coletividades locais dos dois Estados, considerando as legislações internas de cada EstadoParticipante e o que é mais interessante, em termos sociais, é que representantes das sociedades envolvidas pela área fronteiriça podem participar dos trabalhos das diversas comissões. Esse artigo se destaca por envolver a sociedade civil na execução dos programas e ações de planejamento tendo como subsídio o Acordo.

Os artigos sétimo e oitavo tratam das ab-rogações de Tratados anteriores, ou seja, a revogação total de outros Atos Internacionais firmados entre o Brasil e a França. É importante destacar que não são ab-rogados todos os Tratados firmados entre esses dois Estados, mas os que têm relação direta com este. Ou seja, pela edição deste, consideram-se alguns Atos entre os dois Estados nulos ou sem efeito, principalmente os relacionados as questões econômicas, culturais e de fronteira, conforme se observa a seguir:

a) o artigo 12 do Acordo Cultural entre o Governo da República dos Estados Unidos do Brasil e o Governo da República Francesa, firmado em 6 de dezembro de 1948;

b) o Acordo, por troca de Notas, entre o Governo da República dos Estados Unidos do Brasil e o Governo da República Francesa, que cria uma Comissão Mista francobrasileira de desenvolvimento econômico, firmado em 24 de abril de 1954;

c) o Acordo entre o Governo da República Federativa do Brasil e o Governo da República Francesa, que constitui uma Grande Comissão, firmado em 24 de outubro de 1975.

Artigo 8:

A lista dos Acordos em vigor será estabelecida após exame conjunto pelas Partes Contratantes. Os acordos omitidos nessa lista não serão considerados como automaticamente ab-rogados, salvo se as Partes Contratantes assim convierem (BRASIL. Decreto no 2.200/1997, art. 7ㅇ e 8o - Anexo).

Na prática a ab-rogação, segundo Mazzuoli (2011), é comum, principalmente quando os Estados participantes do Tratado já instituíram Atos Internacionais anteriores, como é o caso do Brasil e da França que estabeleceram e mantém vários Tratados, nas suas mais diversas tipologias e com os mais diferentes interesses.

$\mathrm{O}$ artigo nono se refere às formalidades que a Convenção de Viena, de 1969 determina, ou seja, a notificação entre os dois interessados quando dos procedimentos constitucio- 
nais e legais internos necessários para que o Acordo-Quadro entre em vigor. Além de prever as denúncias sobre o Acordo entre o Brasil e a França, conforme exposto a seguir:

1. Cada uma das Partes Contratantes notificará a outra do cumprimento das respectivas formalidades constitucionais e legais internas requeridas para a entrada em vigor do presente Acordo, que terá efeito no primeiro dia do mês seguinte à data de recepção da segunda notificação.

2. O presente Acordo poderá ser denunciado a qualquer momento por qualquer uma das Partes Contratantes, por via diplomática. A denúncia surtirá efeito 6 (seis) meses depois da data do recebimento da notificação respectiva. (BRASIL. Decreto no 2.200/1997, art. 9o - Anexo).

Em síntese, o Acordo-Quadro, assinado em 1996 foi elaborado conforme as formalidades da Convenção de Viena, de 1969, e expõe uma série de ações que visam promover o desenvolvimento socioeconômico da área fronteiriça do Amapá com a Guiana Francesa. Entretanto, é perceptível que o Acordo permanece no campo do planejamento, sem que ações e programas práticos sejam executados, tornando a convivência entre os dois povos, muitas vezes conflituosas.

Contudo, é importante destacar que se este Acordo for executado em conformidade com o que pressupõe os seus artigos, a região de fronteira entre o Amapá e a Guiana Francesa pode ter um desenvolvimento amparado na cooperação econômica, cultural, científica e técnica, o que deve ser benéfico os dois Estados, diminuindo, assim, a animosidade entre as duas populações e os constantes atos de violência praticados na área de fronteira.

Na perspectiva amapaense a cooperação transfronteiriça é o instrumento que pode viabilizar a integração do Amapá com o Platô das Guianas, por meio da rodovia Transguianense, pois nacionalmente, o Amapá não possui ligação terrestre com os outros estados, permanecendo isolado, e sem desenvolvimento socioeconômico, o que traz grandes prejuízos para a população Amapaense.

Outra importante constatação é que com a assinatura do Acordo-Quadro é possível perceber a transição de uma política para fronteira baseada no princípio da defesa nacional para a concepção de fronteira como área de cooperação, tendo como base a integração regional. Essa perspectiva não abandona os ideais de que a fronteira deixe de ser um espaço de limite entre territórios soberanos, mas, pressupõe que na fronteira deve-se considerar suas potencialidades.

\section{CONSIDERAÇÕES FINAIS}

Este estudo pretendeu analisar como ocorre a dinâmica socioeconômica em uma fronteira internacional e como são elaborados os Atos Internacionais, também denominados de Tratados Internacionais. Sendo analisado em particular a constituição e o estabelecimento do Acordo-Quadro assinado entre o Brasil e a França, em 1996 e ratificado pelo Estado brasileiro em 1997, além de destacar o teor do Acordo, considerando o preâmbulo e o corpo do Tratado. 
Sob o tema O Acordo-Quadro e a Fronteira Internacional do Amapá, e tendo como principal questionamento a inquirição de como se desenvolve a execução deste Acordo na Faixa de Fronteira Amapá-Guiana Francesa. Foi possível confirmar a hipótese, ou seja, não há de fato a execução do Acordo-Quando e que este, ainda, permanece no campo do planejamento, de reuniões e encontros das autoridades brasileira e francesas, sem influenciar no cotidiano das populações da região fronteiriça.

Isto é, no processo de implementação deste Tratado é possível apontar que, embora de grande importância para o desenvolvimento social, econômico, cultural, científico e tecnológico, este Ato não influenciou diretamente na vida das pessoas, que continuam enfrentando graves problemas em praticamente todas as áreas, mas, sobretudo, na área socioeconômica, tendo como desdobramento a constante violência na área, o que traz grandes transtornos à população dos dois lados da fronteira.

Outra constatação importante que a pesquisa chegou, é que a questão do Amapá faz parte da história fronteiriça do Brasil e para que esta fronteira fosse estabelecida, foi necessário uma série de Acordos Internacionais, sobressaindo os interesses dos brasileiros. Porém, os conflitos sobre o território persistem até os dias atuais, sendo indispensável continuar com negociações entre os governos do Brasil e da França.

Constatou-se, ainda, que os Atos Internacionais atualmente têm amplitude que envolve praticamente todos os países e abrange temas variados e sem estes instrumentos seria difícil manter a ordem e a paz mundial, pois são eles que celebram os Acordos econômicos, territoriais e de segurança internacional e se caracterizam por terem a mesma identidade jurídica material, independentes de seu processo e terminologia.

E finalmente foi possível perceber a necessidade urgente de execução do AcordoQuadro, pois a população dos dois lados da fronteira precisa dos desdobramentos deste Acordo para tentar ter uma vida digna, calcada no desenvolvimento socioeconômico, para que a violência seja diminuída. Isto é, o Acordo preconiza uma série de medidas, que de modo geral, melhoraria a situação das populações humanas, mas como de fato não foram implementadas, as pessoas alimentam expectativas que são urgentes e imprescindível a paz na fronteira.

\section{REFERÊNCIAS}

BRASIL. Constituição (1988). Constituição da República Federativa do Brasil. Brasília, DF: Senado, 1988.

. Decreto Legislativo no 5, de 1997. Aprova o texto do Acordo-Quadro sobre Cooperação celebrado entre o Governo da República Federativa do Brasil e o Governo da República Francesa, em Paris, em 28 de maio de 1996.

. Decreto no 2.200, de 08 de abril de 1997 - Promulga o Acordo-Quadro de Cooperação, celebrado entre o Governo da República Federativa do Brasil e o Governo da República Francesa, em Paris, em 28 de maio de 1996. Publicado no Diário Oficial da União em 09.04.1997. 
BRITO, Daguinete Maria Chaves. Conflitos socioambientais na gestão de unidades de conservação: o caso da Reserva Biológica do Lago Piratuba/AP. Tese de Doutorado. Programa de Pós-Graduação em Ciências Sociais. Universidade Federal do Pará. Pará.

COELHO, Pedro Motta Pinto. Fronteiras na Amazônia: Um Espaço Integrado. Brasília: Fundação Alexandre de Gusmão, 1992. (Relações Internacionais).

GÓES, David Souza. Garimpagem de Ouro na Fronteira Amapá Guiana Francesa: Subsídios para políticas públicas. Dissertação de Mestrado em Direito Ambiental e Políticas Públicas. UNIFAP: Macapá, 2014.

LAFER, Celso. Política Externa Brasileira: Reflexão e Ação. In MARCOVITCH, Jacques (org.). Cooperação Internacional: Estratégia e Gestão. São Paulo: Editora da Universidade de São Paulo, 1994.

MARTINS, Carmentilla das Chagas. Relações bilaterais Brasil/França: a nova perspectiva brasileira para a fronteira Amapá/Guiana Francesa no contexto global. Dissertação de Mestrado em História. UnB: Brasília, 2008.

MAZZUOLI, Valério de Oliveira. Curso de Direito Internacional Público. 5a Ed. Rev. Atual. São Paulo. Editora Revista dos Tribunais, 2011.

MELLO, Celso Albuquerque de. Direito internacional Público. 15ạ Ed. Rio de Janeiro: Renovar, 2004

PIOVESAN, Flávia. Direitos Humanos e o Direito Internacional. 5a Ed. Editora: Max Limonad, 2003.

PORTELA, Paulo Henrique Gonçalves. Direito Internacional Público e Privado. 6ạ Ed. Rev. Amp. Atual. Salvador. Editora Jus Podivm, 2014.

Artigo recebido em 01 de março de 2018.

Aprovado em 24 de abril de 2018. 